\title{
Influence of Stress State on the Yield Strength of Aluminium Alloy
}

Jiri Sobotka, Pavel Solfronk, David Korecek

Department of Engineering Technology, Technical University of Liberec. Studentská 1402/2, 46117 Liberec. Czech Republic. E-mail: jiri.sobotka@tul.cz, pavel.solfronk@tul.cz, david.korecek@tul.cz

The basic mechanical properties of structural materials (e.g. yield strength, ultimate tensile strength, uniform and total ductility, anisotropy coefficient, etc.) represent fundamental material characteristics. These parameters are mostly detected by a static tensile test. From the stress state point of view, it is therefore a uniaxial tension stress state. However, the service load usually means acting of wide range of stress states. For this reason, the department of engineering technology at TUL developed a device enabling loading the sample by planar bi-axial loading with the possibility to change ratio of their loading. It is therefore possible to load the material from uniaxial tension to equi-biaxial stretching. The aim of this paper is to determine the change of one basic material mechanical properties (yield strength) based on the adjustment of various stress states - from the conventional uniaxial tensile stress state (static tensile test) to equi-biaxial stretching. The own evaluation is performed on the measured stress-strain curves for the tested aluminium alloy AA6111. The results can then be used not only to describe the effect of stress state on the deformation behaviour of tested material, but can also serve as input data in numerical simulations of forming technologies.

Keywords: Stress state, Yield Strength, Aluminium Alloy, Contact-less Optical Measurement, Bi-axial Testing

\section{Introduction}

Aluminium alloys represents more and more interesting material group - especially with respect to their density that makes possible to reduce the weight of products [1]. And that is why it is quite important to properly determine also their deformation behaviour not only by the most common material test - static tensile test. That is why in this paper were investigated chosen mechanical properties (mainly yield strength, but also approximation constants) in dependence on different both stress state $\mathrm{m}_{\sigma}[1]$ (ratio of minor stress $\sigma_{2}$ and major stress $\sigma_{1}$ ) and strain state $\mathrm{m}_{\varphi}$ [1], which means ratio of minor strain $\varphi_{2}$ and major strain $\varphi_{1}$. Regarding the sheet metal forming (used in this paper), $\sigma_{3}=0$ and $\varphi_{3}$ (termed as thickness reduction) was computed from the constant volume law $\left(\varphi_{1}+\varphi_{2}+\varphi_{3}=0\right)$. So beside the common static tensile test, there was performed also hydraulic bulge test and planar bi-axial test (on the totally new jig). In addition to that, contact-less optical system MERCURY RT to determine distribution of strain was used as well.

As a tested material there was chosen the aluminium alloy AA6111 (thickness $0.9 \mathrm{~mm}$ ) from the foreign producer AMAG Austria Metall AG. It is material quite similar to the aluminium alloy AA6082, just with a significant addition of copper [2]. By conventional blanking there were prepared testing samples for static tensile test and hydraulic bulge test. In the case of planar bi-axial test there was necessary to apply plasma cutting, because of their cross-like shape.

Static tensile test was carried out under the common conditions (room temperature and strain rate $\mathrm{c}=0.002 \mathrm{~s}^{-1}$ ) and for all important rolling direction (RD) - marked as $0^{\circ}, 45^{\circ}$ and $90^{\circ}$ (regarding rolling direction). Tab. 1 summarizes the major relevant material property in this paper- proof yield strength $R_{\mathrm{p} 0.2} \quad[\mathrm{MPa}]$ and also approximations constants that are used in the numerical simulation for material deformation behaviour in the region of plastic deformation - strength coefficient C [MPa], strain hardening exponent $\mathrm{n}[1]$ and so-called offset of strain $\varphi_{0}[1]$. These constants are arising from the socalled Krupkowsky hardening curve (see equation 1):

$$
\sigma=C\left(\varphi+\varphi_{0}\right)^{n}
$$

Nevertheless, generally equation 1 has to be rewritten a little, because except static tensile test, there is necessary to always compute so-called effective stress $\sigma_{\text {eff }}[\mathrm{MPa}]$ and effective strain $\varphi_{\text {eff }}[1]$. Only for static tensile test is valid that $\sigma_{\text {eff }}=\sigma_{1}=\sigma$ and $\varphi_{\text {eff }}=\varphi_{1}$ (uni-axial tensile stress state) [3]. Computation of effective stress $\sigma_{\text {eff }}$ and effective strain $\varphi_{\text {eff }}$ for the hydraulic bulge test and planar bi-axial test is always mentioned on the relevant pages. 
Tab. 1 Static tensile test-basic material characteristics of $A A 6111$

\begin{tabular}{|c|c|c|c|c|c|c|}
\hline \multicolumn{3}{|c|}{ Testing conditions } & \multicolumn{4}{|c|}{ Proof yield strength and approximation constants } \\
$\begin{array}{c}\text { Stress } \\
\text { ratio }\end{array}$ & $\begin{array}{c}\text { Strain } \\
\text { ratio }\end{array}$ & $\begin{array}{c}\text { Rolling } \\
\text { direction }\end{array}$ & $\begin{array}{c}\text { Proof yield } \\
\text { strength }\end{array}$ & $\begin{array}{c}\text { Strength } \\
\text { coefficient }\end{array}$ & $\begin{array}{c}\text { Strain harden- } \\
\text { ing } \\
\text { exponent }\end{array}$ & Offset of strain \\
$\mathrm{m}_{\square}[1]$ & $\mathrm{m}_{\square}[1]$ & $\alpha\left[^{\circ}\right]$ & $\mathrm{R}_{\mathrm{p} 0.2[\mathrm{MPa}]}$ & $\mathrm{C}[\mathrm{MPa}]$ & $\mathrm{n}[1]$ & $\varphi_{0}[1]$ \\
\hline \multirow{2}{*}{0} & & $0^{\circ}$ & 141.8 & 492.34 & 0.2681 & 0.0052 \\
& -0.5 & $45^{\circ}$ & 134.4 & 473.78 & 0.2688 & 0.0059 \\
& & $90^{\circ}$ & 133.0 & 473.55 & 0.2724 & 0.0055 \\
\hline
\end{tabular}

\section{Measurement of the Hydraulic Bulge Test}
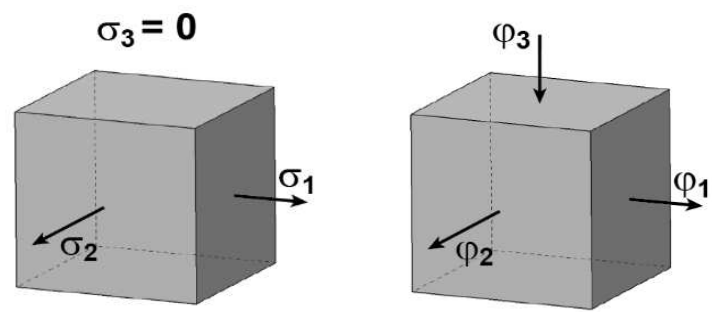

Fig. 1 Hydraulic bulge test - stress state (left) and strain state (right)

Hydraulic bulge test represents type of material testing, where tested specimen is subjected to socalled equi-axial stretching (or equi bi-axial loading). It means that material is loaded uniformly $\left(\sigma_{1}=\sigma_{2}\right)$ at both axes that are in light of deformation taken generally as major strain $\varphi_{1}$ and minor strain $\varphi_{2}$ (also the same in this case). To ensure such conditions, there is mostly used hydraulic fluid (sometimes there is used compressed air for very thin materials as are e.g. aluminium foils) and circular shape of specimen. Beside the measurement deformation material properties (especially approximation constants) is this kind of test used at measurement the forming limit diagrams (to be more specific its right part corresponding to the equi bi-axial stretching). Relevant stress and strain state are shown in Fig. 1.

Regarding the deformation conditions, stress ratio $\mathrm{m}_{\square}$ and strain ratio $\mathrm{m}_{\square}$ can be quite apparently characterized just according to another term that is used to describe the hydraulic bulge test - thus equi bi-axial loading. So in this case are both stress and strain conditions summarized as $\sigma_{1}=\sigma_{2}$ and $\sigma_{3}=0$ for stress state and $\varphi_{1}=\varphi_{2}$ for strain state. Based upon these conditions, stress ratio $\mathrm{m}_{\square}$ and strain ratio $\mathrm{m}_{\square}$ for the hydraulic bulge test can be summarized as following:

$$
\begin{aligned}
& m_{\sigma}=\frac{\sigma_{2}}{\sigma_{1}}=\frac{1}{1}=1 \\
& m_{\varphi}=\frac{\varphi_{2}}{\varphi_{1}}=\frac{1}{1}=1
\end{aligned}
$$

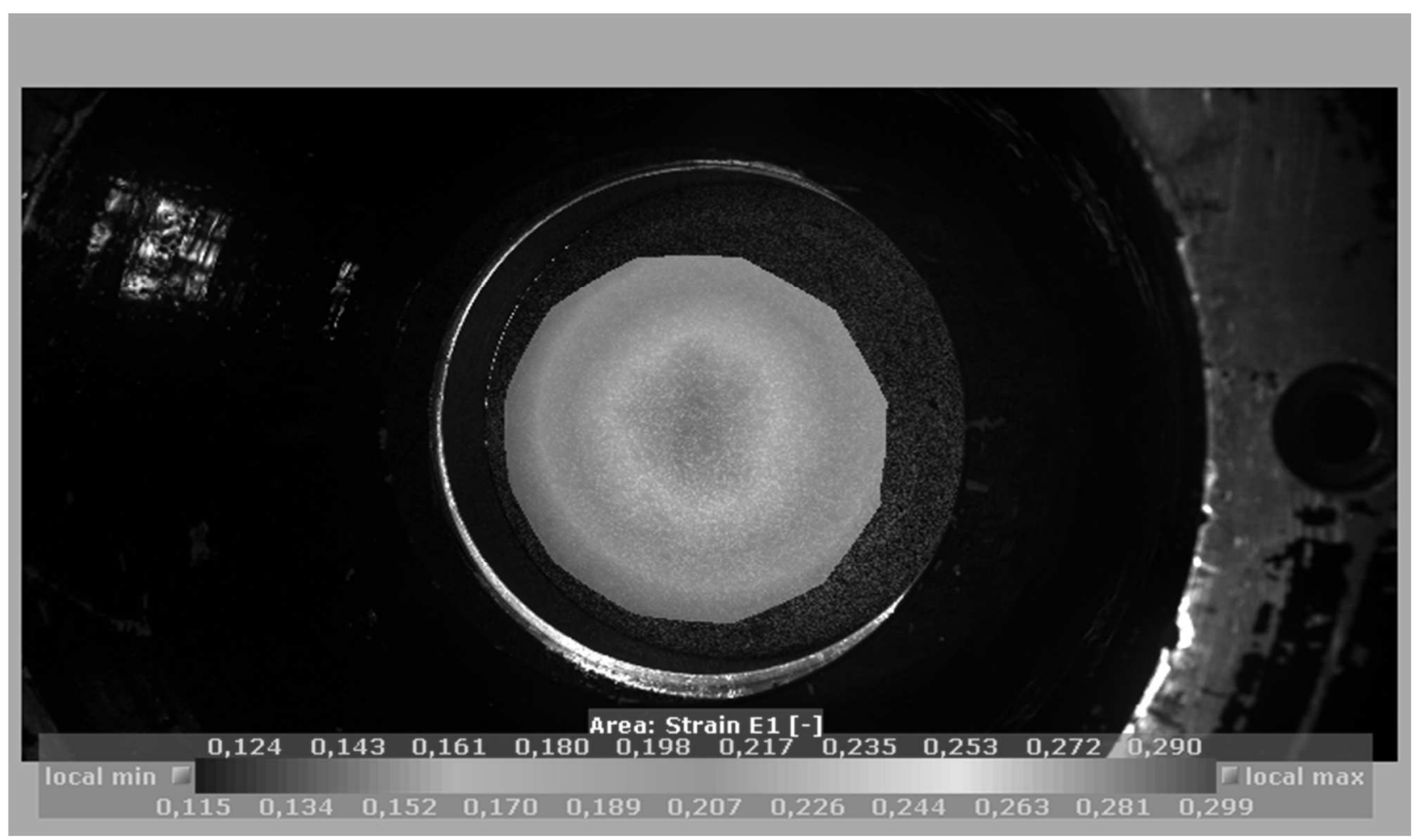

Fig. 2 Distribution of major strain $\varphi_{1}$ right before fracture 
Fig. 2 shows stage right before the fracture as a distribution of major strain $\varphi_{1}$ [1] on the surface of tested aluminium alloy under conditions of the hydraulic bulge test as a distribution of major strain $\varphi_{1}$ [1] on the surface of tested material. There was used a jig that consists of two halves. The lower part serves for inlet of hydraulic fluid and the upper part is generally used for clamping tested specimen. Moreover, this part of jig was designed as open to enable scanning the surface of measured material by the cameras within the contact-less optical

$$
\begin{gathered}
\sigma_{e f f}=\frac{1}{\sqrt{2}} \cdot \sqrt{\left(\sigma_{1}-\sigma_{2}\right)^{2}+\left(\sigma_{2}-\sigma_{3}\right)^{2}+\left(\sigma_{3}-\sigma_{1}\right)^{2}} \\
\varphi_{e f f}=\frac{\sqrt{2}}{3} \cdot \sqrt{\left(\varphi_{1}-\varphi_{2}\right)^{2}+\left(\varphi_{2}-\varphi_{3}\right)^{2}+\left(\varphi_{3}-\varphi_{1}\right)^{2}}
\end{gathered}
$$

Moreover, there can be derived that for the hydraulic bulge test, where $\sigma_{1}=\sigma_{2}$ and $\sigma_{3}=0$, is valid that $\sigma_{\text {eff }}=\sigma_{1}$. And finally, according to membrane analogy for symmetric shells is also valid:

$$
\sigma_{e f f}=\sigma_{1}=\frac{p \cdot R}{2 \cdot t}
$$

Where:

p- applied pressure[MPa],

$\mathrm{R}$ - radius of curvature[mm],

$\mathrm{t}-$ actual thickness[mm]. deformation measurement.

As it was already mentioned before, stress-strain curves have to be computed, expect the uniaxial stress state, via effective stress $\sigma_{\text {eff }}[\mathrm{MPa}]$ and effective strain $\varphi_{\text {eff }}$ [1]. These values are acc. to stress tensor theory computed based upon so-called principal stresses $\left(\sigma_{1}\right.$ - major stress, $\sigma_{2}-$ minor stress and $\sigma_{3}-$ stress in the thickness direction) and principal strains $\left(\varphi_{1}-\right.$ major strain, $\varphi_{2}-$ minor strain and $\varphi_{3}-$ strain in the thickness direction) as following:

Tab. 2 Hydraulic bulge test-basic material characteristics of AA6111

\begin{tabular}{|c|c|c|c|c|c|}
\hline \multicolumn{2}{|c|}{ Testing conditions } & \multicolumn{4}{|c|}{ Proof yield strength and approximation constants } \\
$\begin{array}{c}\text { Stress } \\
\text { ratio }\end{array}$ & $\begin{array}{c}\text { Strain } \\
\text { ratio }\end{array}$ & Proof yield & Strength & Strain hardening & Offset of strain \\
$\mathrm{m}_{\square}[1]$ & $\mathrm{m}_{\square}[1]$ & $\mathrm{R}_{\mathrm{p} 0.2[\mathrm{MPa}]}$ & $\begin{array}{c}\text { coefficient } \\
\text { exponent }\end{array}$ & $\mathrm{CPa}$ \\
\hline 1 & 1 & 119.8 & 504.278 & 0.3033 & $\varphi_{0}[1]$ \\
\hline
\end{tabular}

From the contact-less optical system MERCURY RT was determined radius of curvature R (see Fig. 3) and from the distribution of major strain $\varphi_{1}$ and minor strain $\varphi_{2}$ (for distribution of $\varphi_{1}$ see Fig. 2) can be also computed actual thickness (via $\left.\varphi_{3}\right)$. As a result there is stress-strain curve, where can be determined yield strength and also computed approximation constants. These characteristics (as average of 3 tests) are summarized in Tab. 2 and shown in Fig. 7.

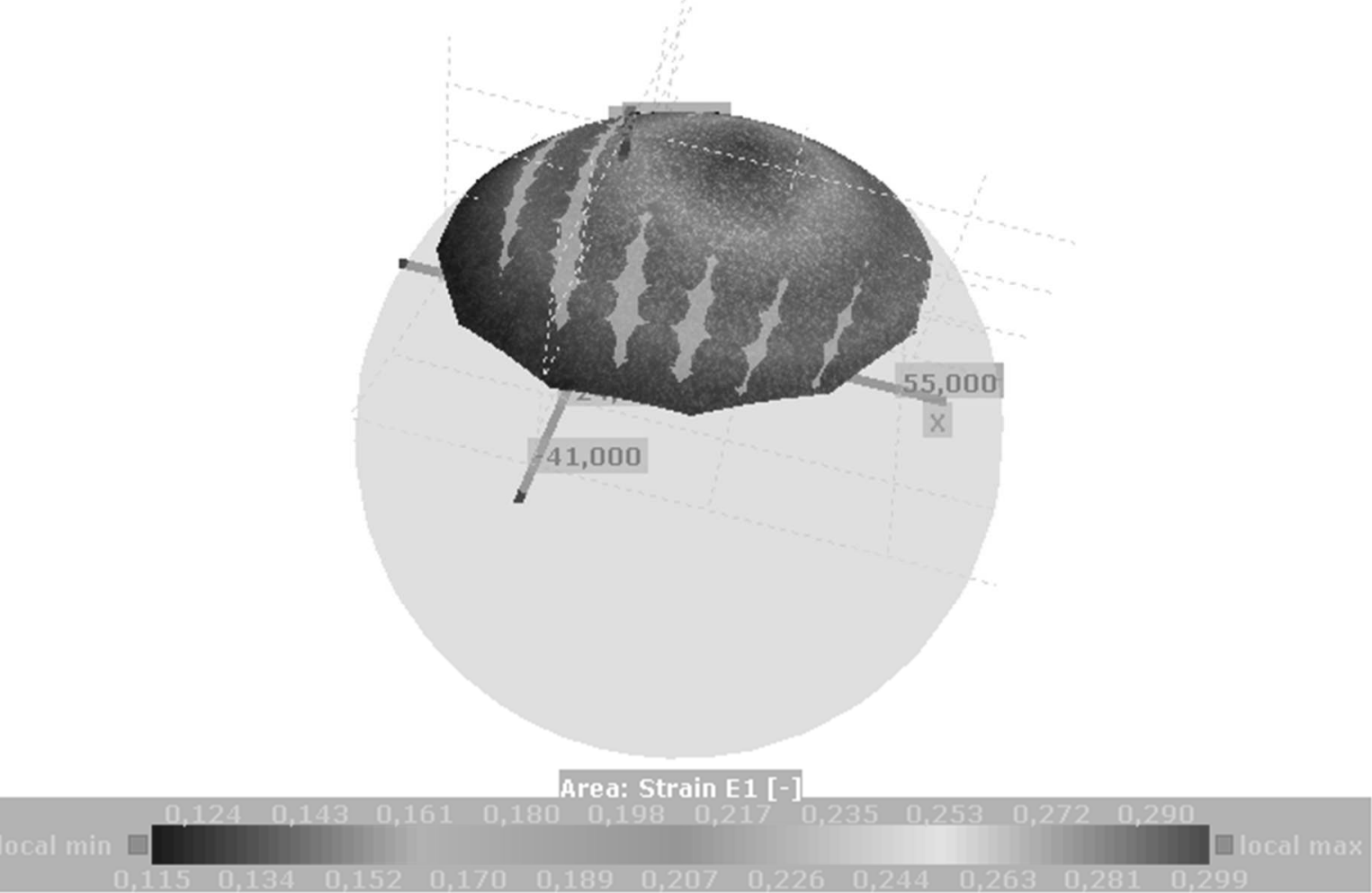

Fig. 3 Procedure how to determine radius of curvature $\mathrm{R}$ during bydraulic bulge test 
Fig. 3 illustrates the procedure how to determine radius of curvature $\mathrm{R}$ from hydraulic bulge test. There is shown not only own distribution of major strain $\varphi_{1}$ [1] right before the fracture of specimen (the same one as in Fig. 2), but also sphere (grey colour) that was computed as best-fit in this stage. And its radius is required radius of curvature.

\section{Measurement of the Planar Bi-axial Test}

At the Department of Engineering Technology (TU of Liberec) was designed the new planar bi-axial testing machine (see Fig. 5) that generally consists of two pairs of cylinders (thus totally four cylinders), which deformed tested specimen under different stress and strain states. Fig. 4 graphically shows applied stress and strain states in measurement the material deformation behaviour under planar bi-axial testing for this paper.
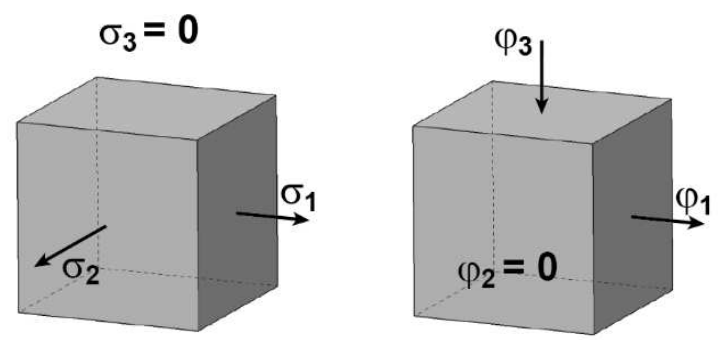

Fig. 4 Planar bi-axial test-applied stress state (left) and strain state (right)
Generally, planar bi-axial testes makes possible to test any combination of planar stress states (from the static tensile test to the hydraulic bulge test). In this paper were used conditions, which are theoretically taken to be in the middle between those two limits. Thus, in light of stress state, there was applied planar bi-axial condition, which can be according to the generalised Hooke's law described as following: $\sigma_{2}=$ $0.5 \cdot \sigma_{1}$ and $\sigma_{3}=0$. Regarding the deformation, there was applied loading via cylinders only in one direction (taken as $\varphi_{1}$ ), while in the other direction was testing specimen just clamped without movement of relevant cylinder - so $\varphi_{2}=0$. Based upon these conditions, stress ratio $m_{\sigma}$ and strain ratio $m_{\varphi}$ can be summarized as following:

$$
\begin{aligned}
& m_{\sigma}=\frac{\sigma_{2}}{\sigma_{1}}=\frac{\frac{1}{2} \cdot \sigma_{1}}{\sigma_{1}}=\frac{1}{2} \\
& m_{\varphi}=\frac{\varphi_{2}}{\varphi_{1}}=\frac{0}{\varphi_{1}}=0
\end{aligned}
$$

Fig. 5 shows the own arrangement of the planar biaxial testing machine that was equipped with the cameras to use contact-less deformation measurement in this case. To control the whole process, there are four individual control panels - each of them for the relevant cylinder (no. $1-4$ ). Every control panel is then adjusted to measure force $[\mathrm{N}]$ and position of the cylinder $[\mathrm{mm}]$ during the own test.

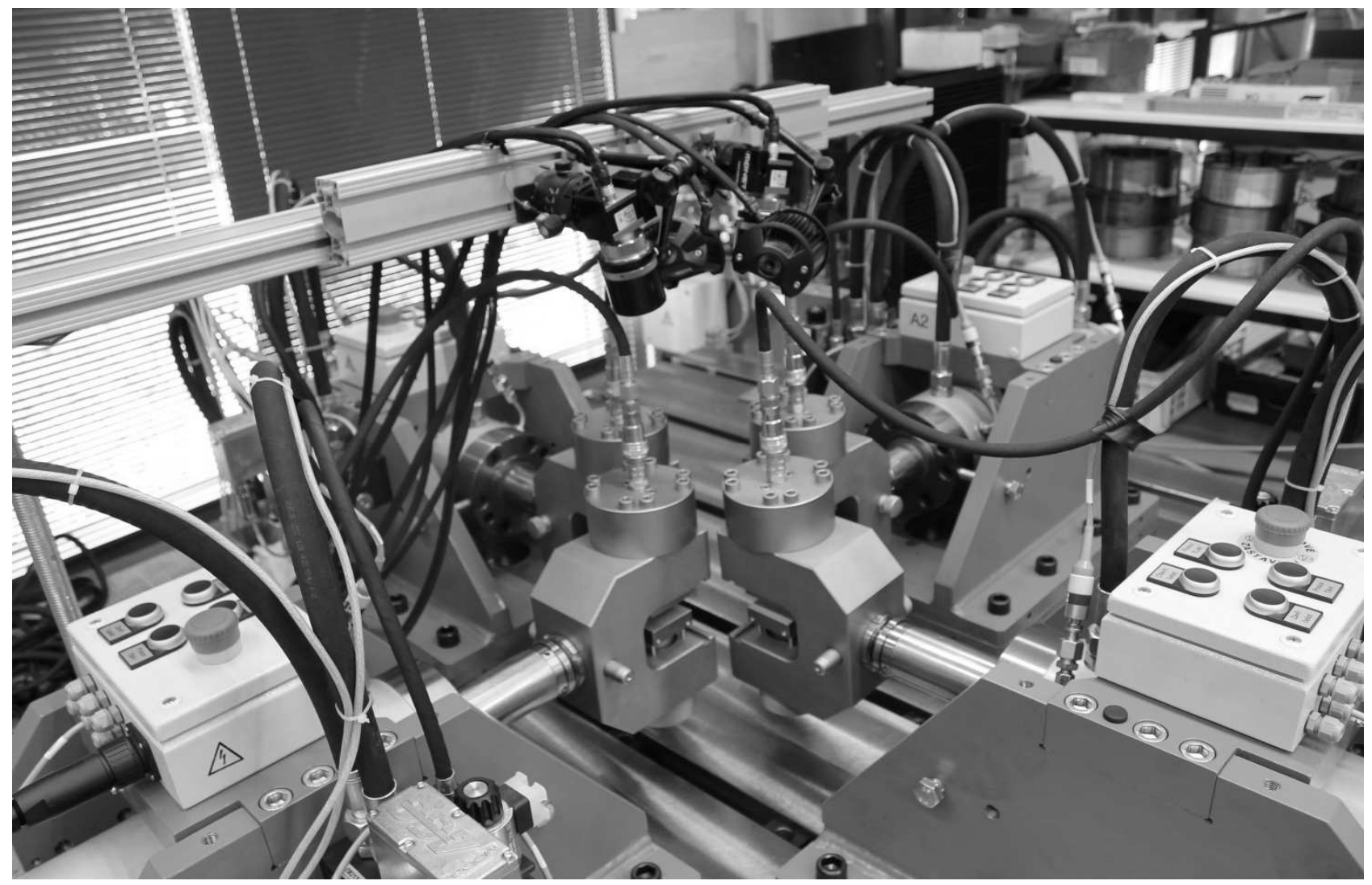

Fig. 5 Arrangement of the planar bi-axial test 
The same contact-less optical system (MERCURY RT from the company Sobriety Ltd.) as in the case of the hydraulic bulge test, was used also in the measurement of the planar bi-axial test. The first needed step was to accurately positioned cameras in light of their distance from the surface of tested specimen and also with respect to its centre. Again, there was necessary to adjust the proper focusing as well as the relevant shutter time of both objectives. After that, the whole contact-less optical system for measurement the planar bi-axial test, was calibrated.

Geometrical shape of tested specimen was chosen according to experience of the Department of Engineering Technology at TUL. For preparation of the own shape was used plasma cutting. Generally it can be stated that specimens have a cross shape, where special attention is given to its radii. For the final used shape see Fig. 6. After plasma cutting it was needed to degrease surface of specimen before application of stochastic pattern via spraying white and black colours. Finally, testing specimen was placed in the middle of tested cylinders (Fig. 6), its position was fixed by the clamping jaws and required deformation conditions (see previous page) were adjusted.

The planar bi-axial tester primarily measured the courses of forces $[\mathrm{N}]$ in given two directions and positions of cylinders [mm]. As a result there can be computed effective stress $\sigma_{\text {eff }}[\mathrm{MPa}]$. These signals are added as input data channels into optical system. In addition to that, from the images, which are scanned from the contact-less optical system MERCURY RT are measured values both of the major strain $\varphi_{1}[1]$ and minor strain $\varphi_{2}$ [1]. Thus from the constant volume law, there are also values of thinning $\varphi_{3}$ [1]. And based upon these result, there can be computed effective strain $\varphi_{\text {eff }}$ [1]. Finally, the relevant stress-strain curve under tested conditions can be plotted and all required material characteristics are given by it. Tab. 3 summarized such properties for performed planar biaxial test. Own stress-strain curve shape is shown (together with other stress states - tensile test and hydraulic bulge test) in Fig. 7.

Tab. 3 Planar bi-axial test-basic material characteristics of A A6111

\begin{tabular}{|c|c|c|c|c|c|}
\hline \multicolumn{3}{|c|}{ Testing conditions } & \multicolumn{4}{|c|}{ Proof yield strength and approximation constants } \\
$\begin{array}{c}\text { Stress } \\
\text { ratio } \\
\mathrm{m}_{\square}[1]\end{array}$ & $\begin{array}{c}\text { Strain } \\
\text { ratio } \\
\mathrm{m} \square[1]\end{array}$ & $\begin{array}{c}\text { Proof yield } \\
\text { strength } \\
\mathrm{R}_{\mathrm{p} 0.2[\mathrm{MPa}]}\end{array}$ & $\begin{array}{c}\text { Strength } \\
\text { coefficient } \\
\mathrm{C}[\mathrm{MPa}]\end{array}$ & $\begin{array}{c}\text { Strain hardening } \\
\text { exponent } \\
\mathrm{n}[1]\end{array}$ & $\begin{array}{c}\text { Offset of strain } \\
\mathrm{y}_{0}[1]\end{array}$ \\
\hline 0.5 & 0 & 130.4 & 482.635 & 0.2835 & 0.0019 \\
\hline
\end{tabular}

Fig. 6 illustrates the process of measuring the planar bi-axial test by utilization of the optical contactless system. There is shown the distribution of minor strain $\varphi_{2}$ [1] in the scanning area (center of testing specimen) with the relevant scale below. Take note of characteristic "cross" distribution of displayed minor strain $\varphi_{2}$.

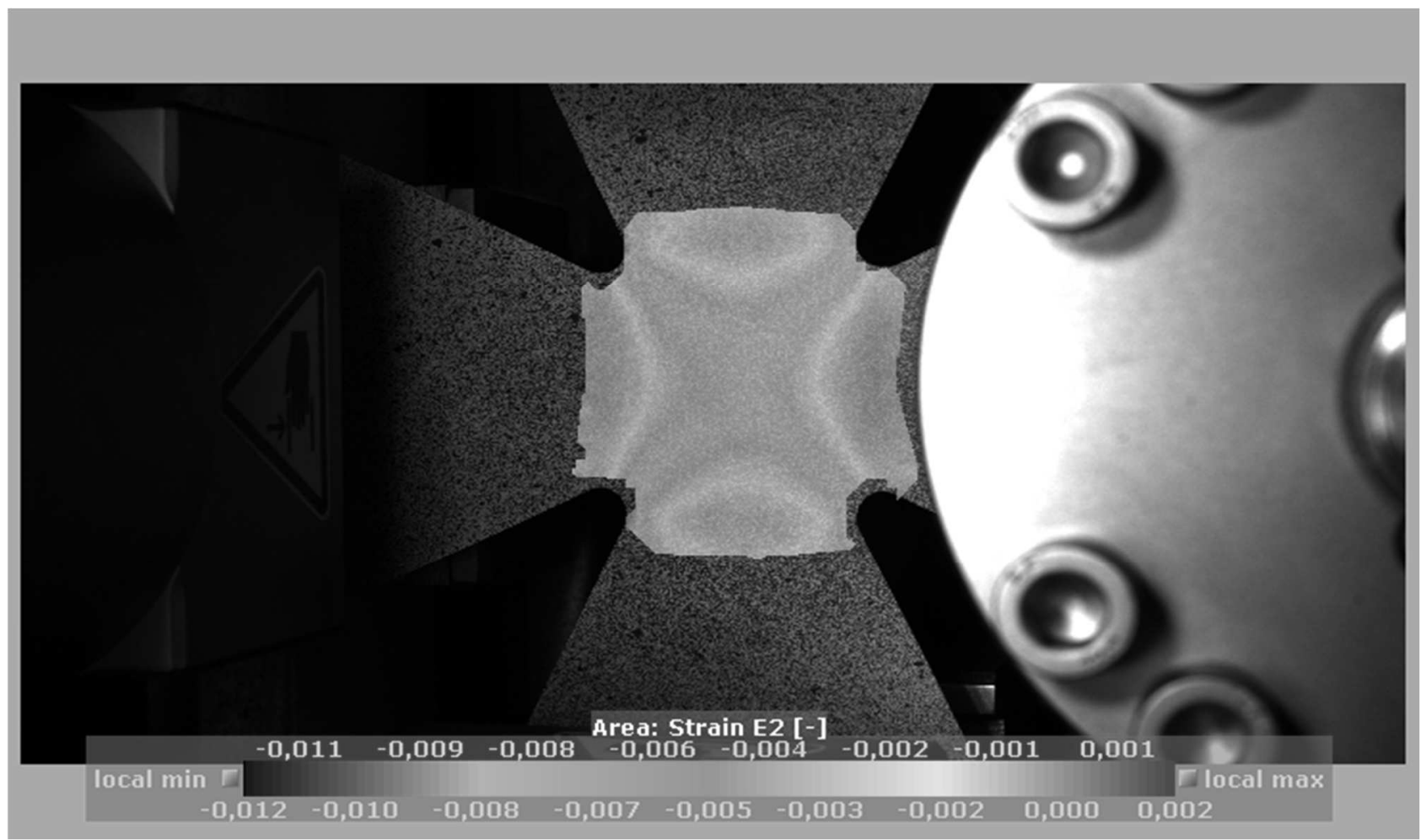

Fig. 6 Distribution of minor strain $\varphi_{2}$ during planar bi-axial test 


\section{Conclusion}

The main purpose of this paper was to evaluate the influence of stress state on the resulting yield strength and also on the approximation constants (strength coefficient $\mathrm{C}$, strain hardening exponent $\mathrm{n}$ and offset of strain $\left.\varphi_{0}\right)$ acc. to Krupkowsky hardening curve in the region of plastic deformation. As a tested material there was used aluminium alloy AA6111 of thickness $0.9 \mathrm{~mm}$. Totally three material tests were applied in the experimental part - static tensile test, planar bi-axial test and hydraulic bulge test. Stress and strain states for the static tensile test and hydraulic bulge test are already arising from these tests: $\mathrm{m}_{\sigma}=0$ and $\mathrm{m}_{\varphi}=-0,5$ for static tensile test and $\mathrm{m}_{\sigma}=1$ and $\mathrm{m}_{\varphi}=1$ for hydraulic bulge test. Planar bi-axial test can be operated under different stress conditions, in this case was used $m_{\sigma}=0,5$ and $m_{\varphi}=0$. To properly evaluate relevant mechanical properties, in the case of hydraulic bulge test and planar bi-axial test was needed to apply contact-less optical system MERCURY RT to scan distribution of relevant strain. From the measured data were finally plotted stress-strain curves (effective stress $\sigma_{\text {eff }}$ vs effective strain $\varphi_{\text {eff }}$ ) and required material properties were compared. Regarding the rolling direction (RD) - static tensile test was done for all major $\mathrm{RD}\left(0^{\circ}, 45^{\circ}\right.$ and $\left.90^{\circ}\right)$, planar bi-axial test was done just for $\mathrm{RD} 0^{\circ}$ and in the case of hydraulic bulge isn't rolling direction relevant.

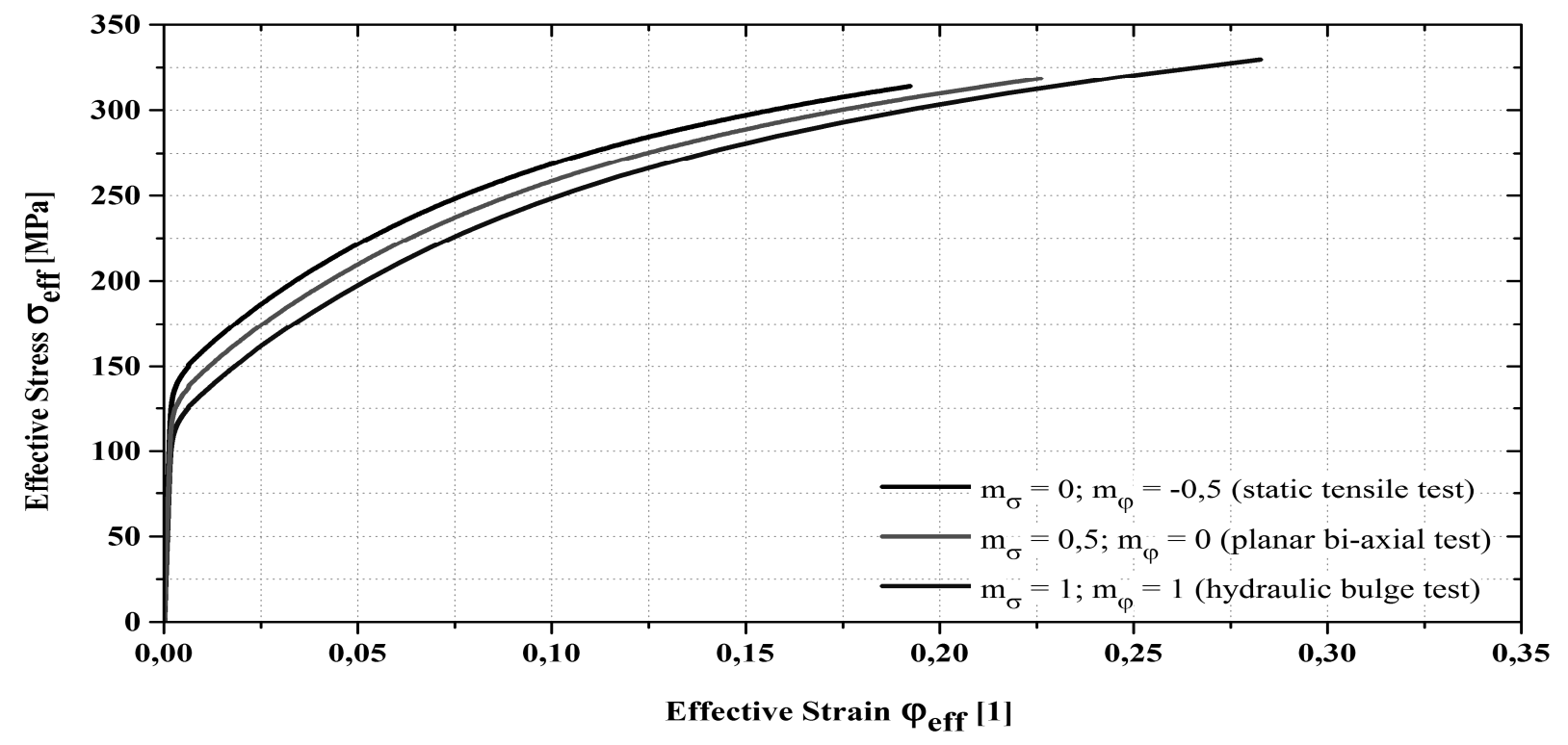

Fig. 7 Final overview of measured stress-strain curves in dependence on different stress states

Detailed explanation how tests were exactly performed was done on the previous pages. Fig. 7 illustrates the most important graphical comparison of measured stress-strain curves in dependence on applied stress and strain states. In light of proof yield

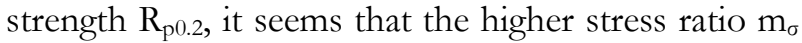
(as well as higher strain ratio $\mathrm{m}_{\varphi}$ ), the lower $\mathrm{R}_{\mathrm{p} 0.2 \text { (to be }}$ specific: $141,8 \mathrm{MPa}-130,4 \mathrm{MPa}-119,8 \mathrm{MPa}$ ). It also means earlier onset of plastic deformation. On the other hand, increasing stress ratio $\mathrm{m}_{\sigma}$ (and again also $\mathrm{m}_{\varphi}$ ) slowly increases values of strength coefficient $C$ and strain hardening exponent $\mathrm{n}$. It means higher tendency of AA6111 for strain hardening (geometrically see Fig. 7). Such knowledge of material deformation behaviour is quite very interesting especially in the case of numerical simulations, where it can provide important input data. On the other hand, in this paper was tested just one aluminium alloy and only under three stress and strain states. There is surely necessary to carry out more tests to proof these first conclusions.

\section{Acknowledgement}

This publication was written at the Technical University of Liberec as part of the project "SGS 21286 " with the support of the Specific University Research Grant, as provided by the Ministry of Education, Youth and Sports of the Czech Republic in the year 2019.

\section{References}

[1] POLMEAR, I. (2006) Ligth Alloy - From traditional Alloys to Nanocrystals, pp. 97-115. Butterworth-Heinemann. Oxford

[2] DAVIES, G. (2003) Materials for Automobile Bodies. pp. 87-91. Butterworth-Heinemann, Oxford.

[3] ASM HANDBOOK. (2000) Volume 8 - Mechanical Testing and Evaluation. pp. 104-130.ASM International. Materials Park. 